\title{
IMPACT OF CLOZAPINE TREATMENT ON SOCIAL FUNCTIONING
}

\author{
Boukhari G., Zgueb Y., Ben Abid I., Ouali U., Jomli R., Meddouri S., Nacef F. \\ boukhari.ghassene@gmail.com \\ Razi Hospital, Avicenne Department, Tunis, Tunisia
}

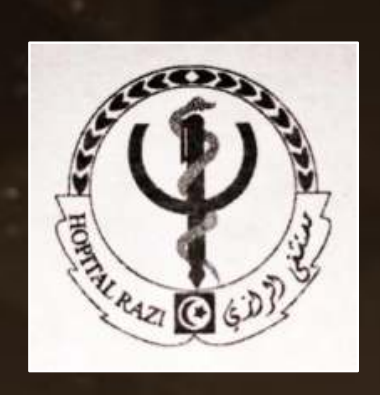

\section{BACKGROUND AND AIMS}

Very few studies ${ }^{[1][2][3][4]}$ have investigated the effect of clozapine treatment on psychosocial functioning, and these studies conclude sometimes contradictory results.. On the other hand, several empirical findings point to a clear improvement on this particular dimension.

We aim therefore to test the hypothesis that clozapine improves psychosocial functioning in patients with severe mental illness.

\section{MATERIALS AND METHODS}

This is a retrospective, longitudinal study on 47 clozapine-treated patients with schizophrenia, schizoaffective disorder, and bipolar disorder according to DSM-5.

Professional, marital, and interpersonal status were evaluated before and after the implementation of clozapine. Furthermore, Global Assessment of Functioning (GAF) scale scores were recorded before and 6 months after the introduction of clozapine.

\section{RESULTS AND DISCUSSION}

Regarding marital situation, $100 \%$ of patients in our sample did not change status.

$41 \%$ of patients on clozapine changed professional status from being unemployed to being employed or actively seeking work. Conversely, in 59\% of patients, there was no change in professional status. None of the patients went from being an employee to an unemployed person (see figure 1).

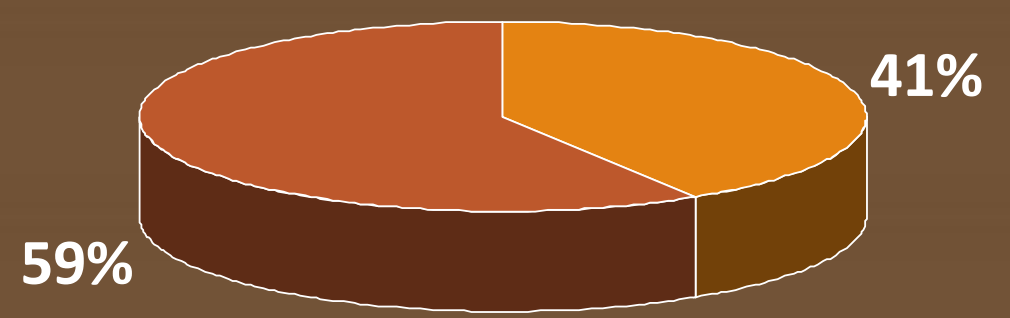

$\square$ Positive change $\square$ No change

Figure 1 Professional status change after CLZ initiation.

Although $41 \%$ do not constitute a majority of patients, we consider this to be a remarkable percentage, since professional integration has a great value in the psychosocial dimension.
$62 \%$ of patients reported a positive change in the interpersonal dimension. The most notable improvement concerned the relationship to the close family ( $56 \%$ improvement), extended family (40\% improvement), and to friends $(40 \%$ improvement). No patient in our sample reported a change in the relationship to the spouse.

Regarding the GAF scale, the average score was 18,9 before, compared with 40 after clozapine initiation, which is $112 \%$ average increase (the range of increase is between $33 \%$ and $800 \%$ ).

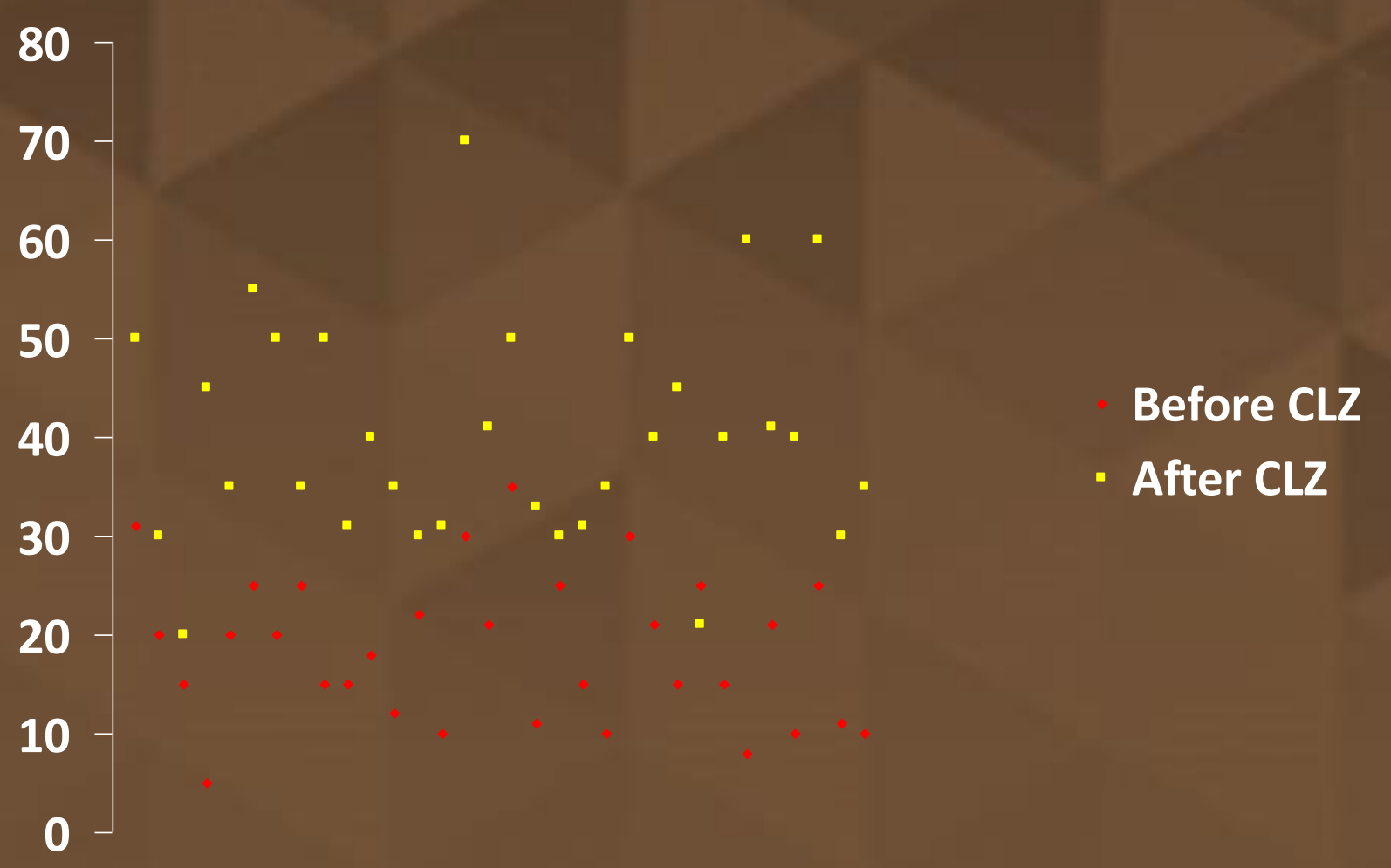

Figure 2 GAF scores before and after CLZ initiation.

These findings contradict the latest published metaanalysis on the subject, which concludes that " $C L Z$ is no better than other antipsychotics for improving psychosocial functioning"[4]. Further exploration of the predictors of good social outcomes with CLZ treatment may improve personalization of care.

\section{CONCLUSIONS}

In conclusion, our study suggests that clozapine has a positive effect on professional and interpersonal functioning, as well as on overall social functioning (using the GAF scale). The sphere least concerned with improvement (be it status or relationship) is the marital sphere.

\section{REFERENCES}

[1] Jonsson D. et al., 1993, Clozapine treatment of patients with schizophrenia. Great improvements with regard to symptoms and social life.

[2] Bellack AS. et al., 2004, Do clozapine and risperidone affect social competence and problem solving?

[3] Smith H. et al., 2004, The Effect of Clozapine on the Social Behaviour Schedule in Patients Attending a Forensic Psychiatry Day Hospital.

[4] Olagunju AT. et al., 2018, Clozapine and Psychosocial Function in Schizophrenia: A Systematic Review and Meta-Analysis. 